\title{
Damage Mechanism of Mineral Admixture Concrete under Marine Corrosion and Freezing-Thawing Environment
}

\author{
Yan Li $\mathbb{D}^{D}$, Lianying Zhang $(\mathbb{D}$, Chao Ma $\mathbb{D}$, Bing Li $\mathbb{D}$, and Jiong Zhu \\ Xuzhou University of Technology, Xuzhou 221008, China \\ Correspondence should be addressed to Chao Ma; mbqq2008@126.com
}

Received 18 September 2020; Revised 28 October 2020; Accepted 5 November 2020; Published 17 November 2020

Academic Editor: Mingfeng Lei

Copyright (c) 2020 Yan Li et al. This is an open access article distributed under the Creative Commons Attribution License, which permits unrestricted use, distribution, and reproduction in any medium, provided the original work is properly cited.

\begin{abstract}
Understanding the performance of concrete in the marine environment is significant for preventing the corrosion of chloride ion for marine buildings. In this study, the uniaxial compressive strength (UCS), chloride ion concentration (CIC), microstructure, and pore structure of admixture concretes were tested to study the mechanical properties and microscopic characteristics under the single marine corrosion, the single freezing-thawing, and the coupled marine corrosion and freezing-thawing conditions. The results indicate that the concrete mixed with both fly ash and mineral powder has better UCS, chloride ion penetration resistance, and freezing-thawing resistance than the concrete with the single fly ash or mineral powder. Under the marine corrosion environment and coupled corrosion and freezing-thawing environment, the UCS of the concrete with both fly ash and mineral powder increases firstly and then decreases with the increase of the corrosion time. This is because the pore of the filling body is filled by large crystalline salts generated by the reaction of chloride ions and concrete; then, cementation of the cement is increased in the early corrosion; meanwhile, the increase of crystal salt in the subsequent corrosion process leads to the growth of microcracks and the formation of macrocracks in concrete specimens. In addition, a freezing-thawing-corrosion composite strength impact factor is introduced to describe the effect of coupled corrosion and freezing-thawing on the mechanical property of the concrete. The results show that the corrosion is the dominant factor after 0,30 , and 60 freezing-thawing cycles, while the freezing-thawing is the dominant factor after 90 freezing-thawing cycles.
\end{abstract}

\section{Introduction}

At present, concrete is the most widely used building material due to its low price, simple production process, high compressive strength, and durability [1-3]. In addition to various construction projects, concrete is also applied in the ship industry, machinery industry, marine development, and geothermal engineering $[4,5]$. With the development of modern engineering and the increasing complexity of engineering structure, ordinary concrete cannot fully meet the needs of modern architecture [6-12]. For example, the durability of concrete structures in sea beaches is always affected by multiple environmental factors (e.g., humidity, freezing-thawing, and chloride ion corrosion) [13], while concrete structures in deep underground engineering may be affected by complex in situ stress and sulfate corrosion [14], and concrete structures in the cold areas (e.g., northeast and northwest China) suffer from freezing-thawing condition [15]. In general, chloride ion corrosion and freezingthawing environment are the most common and important factors in these hazard environments.

A report [16] has pointed out that China annually loses 180 billion to 360 billion yuan (USD 26 billion-USD 52 billion) in civil engineering due to marine corrosion, most of which are caused by chloride ion corrosion [17]. In recent years, research on corrosion resistance of concrete has been highlighted. Different methods have been proposed to improve the durability of concrete in the marine corrosion environment, such as changing the water-binder ratio [18] and the water-cement ratio [19], trying different types of cement [20], and adding admixture (e.g., fly ash and mineral powder) [21]. Besides, the transportation mechanism of chloride ion in concrete [22] and life cycle of concrete in marine corrosion environment have also been widely investigated [23]. 
Freezing-thawing damage is also an important factor affecting the durability of concrete as well [24, 25]. Research has shown that more than $50 \%$ of large concrete structures are damaged in varying degrees by the freezing-thawing environments, especially in northeast China [26]. For example, the damaged surface area of the dam of Yunfeng Hydropower Station in northeast China reaches $10,000 \mathrm{~m}^{2}$ during 10 years after its completion due to freezing and thawing. Experiments on concretes have shown that the strength of concrete decreases with the increase of freezingthawing cycles $[27,28]$. Therefore, the methods of concrete resistance to freezing-thawing have been studied by scholars, and the results indicated that adding fly ash and mineral powder in concrete can resist the freezing-thawing environment $[29,30]$.

Concrete structures at the ports in north China are usually under the coupled effect of marine corrosion and freezing-thawing. However, the damage mechanism of admixture concrete under the coupled marine corrosion and freezing-thawing environment has not been comprehensively explored. In this paper, based on the climate and seawater conditions of the Lianyungang sea (one of the largest ice-free ports in northern China), the macroscopic mechanical properties and microstructures of admixture concrete are systematically explored under three conditions, namely, the single marine corrosion, the single freezingthawing, and the coupled marine corrosion and freezingthawing environment.

\section{Materials}

Portland cement (42.5) employed in this experiment is a commercially available product from China United Cement Co., China. Fly ash and mineral powder are supplied by China United Zhuben Concrete Jiangsu CO., China. The coarse aggregate is made of $5-20 \mathrm{~mm}$ stones and the fine aggregate is medium river sand.

In this study, admixture concrete samples with different water-binder ratios, fly ash $(F)$ contents, and mineral powder $(G)$ contents are prepared as $100 \mathrm{~mm} \times 100 \mathrm{~mm} \times 100 \mathrm{~mm}$ for uniaxial compression test and $100 \mathrm{~mm} \times 100 \mathrm{~mm}$ $\times 300 \mathrm{~mm}$ for relative dynamic elastic modulus test, as shown in Table 1. It can be seen that the concrete formulation includes the following:

(1) The concrete without any admixture (C3-0)

(2) The concrete with $20 \%-50 \%$ fly ash (C3-1, C3-2, C3-3)

(3) The concrete with $50 \%$ mineral powder (C3-5)

(4) The concrete with both $15 \%$ fly ash and $35 \%$ mineral powder (C3-7)

\section{Experimental Methods and Scheme}

3.1. Mechanical Tests. YAS-5000 electrohydraulic servo pressure testing machine (Figure 1(a)) is used to conduct uniaxial compressive tests on admixture concrete. In this experiment, the loading rate is $0.5 \mathrm{MPa} / \mathrm{s}$, and the axial load and displacement are recorded during the loading process.
Relative dynamic elastic modulus is an important characteristic index of concrete under the freezing-thawing condition. TD-W18 dynamic elastic modulus tester (Figure 1(b)) is employed to measure the resonance frequency of concrete specimen, and the UCS of concrete can be calculated by resonance frequency. The relative dynamic elastic modulus of concrete under different freezing-thawing stages is calculated by the following equation:

$$
P=\frac{f_{n i}^{2}}{f_{n 0}^{2}} \times 100 \%,
$$

where $P$ is the relative dynamic elastic modulus of concrete under $N$ freezing-thawing cycles and $f_{n 0}$ and $f_{n i}$ are transverse fundamental frequencies of concrete before and after $N$ freezing-thawing cycles, respectively.

3.2. Microstructure and Pore Structure Tests. Cubic samples are made with a size of $10 \mathrm{~mm} \times 10 \mathrm{~mm} \times 10 \mathrm{~mm}$ from the damaged concrete samples. The Inspect S50 scanning electron microscopy (SEM) is employed to test the microstructure of cubic samples. Before observing the microscopic morphology, the samples are immersed in ethanol and treated with ultrasonic waves and spray-gold. The PoreMaster 60 automatic mercury porosimeter is used to perform the pore structure tests. Before the test, the samples are firstly soaked in alcohol to prevent hydration, and then the samples are dried in the oven.

3.3. Marine Environmental Corrosion. Based on the average temperature of the Lianyungang sea area $(287.9 \mathrm{~K})$ and the laboratory $(304.25 \mathrm{~K})$ [31], the acceleration coefficient of temperature to concrete deterioration $T_{d}$ is determined as 14.27 according to the calculated method of Arrhenius [32].

The mass fraction of sodium chloride $(\mathrm{NaCl})$ is $1.75 \%-$ $2.8 \%$ in the Lianyungang seawater, while the one used in the experiment is $8.33 \%$. Then the acceleration coefficient of chloride ion concentration to corrosion degradation $S_{d}$ is 5.0 , and the acceleration corrosion coefficient in a laboratory test is calculated as 71.35 by $T_{d} \times S_{d}$.

The marine corrosion environments are conducted by the artificial climate simulation laboratory, and the relative humidity in the experiments is set to approximately $80 \%$, which is consistent with that in Lianyungang sea area. The chloride ion concentrations of the samples are measured by the natural diffusion method after corrosion.

3.4. Freezing-Thawing Test. Freezing-Thawing tests are performed on admixture concrete samples by KDS-60 rapid freeze-thaw test machine. In one freezing-thawing cycle, the freezing time and temperature are set as 2 hours and $256 \mathrm{~K}$, respectively, while the thawing time and temperature are set as 1 hour and $281 \mathrm{~K}$, respectively.

3.5. Experimental Scheme. The experimental scheme is shown in Table 2. Firstly, the performance of concrete in the marine environment is explored under the above experimental settings. The corrosion times in the laboratory are 30, 
TABLE 1: The content of different admixture concrete samples.

\begin{tabular}{|c|c|c|c|c|c|c|c|c|}
\hline \multirow{2}{*}{ No. } & \multicolumn{2}{|c|}{ Mineral admixtures } & \multicolumn{4}{|c|}{ Mix proportion of concrete } & \multirow{2}{*}{ Water-binder ratio } & \multirow{2}{*}{ Water $(\mathrm{kg}$} \\
\hline & Category & Content & Cement $(\mathrm{kg})$ & Fly ash $(\mathrm{kg})$ & Mineral powder $(\mathrm{kg})$ & Sand $(\mathrm{kg})$ & & \\
\hline C3-0 & - & - & 453 & - & - & 1852 & 0.32 & 145 \\
\hline C3-1 & $F$ & $20 \%$ & 362 & 91 & - & 1852 & 0.32 & 145 \\
\hline $\mathrm{C} 3-2$ & $F$ & $35 \%$ & 294 & 159 & - & 1852 & 0.32 & 145 \\
\hline $\mathrm{C} 3-3$ & $F$ & $50 \%$ & 226 & 226 & - & 1852 & 0.32 & 145 \\
\hline C $3-5$ & $G$ & $50 \%$ & 226 & - & 226 & 1852 & 0.32 & 145 \\
\hline $\mathrm{C} 3-7$ & $F+G$ & $(15+35) \%$ & 226 & 68 & 158 & 1852 & 0.32 & 145 \\
\hline
\end{tabular}

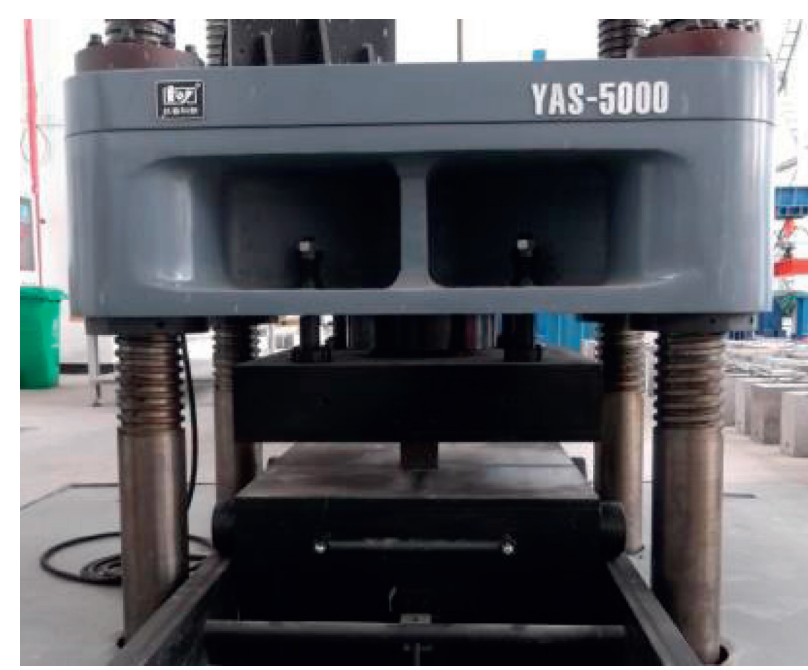

(a)

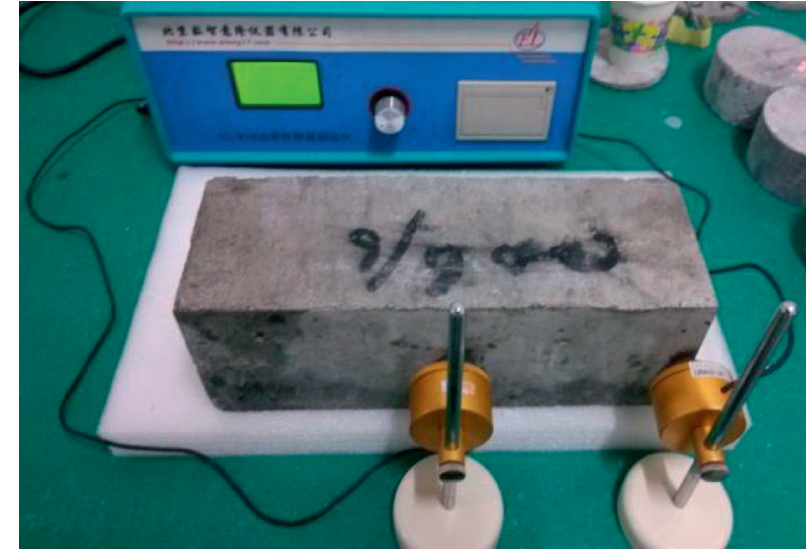

(b)

FIGURE 1: (a) YAS-5000 electrohydraulic servo pressure testing machine and (b) TD-W18 dynamic elastic modulus tester.

TABle 2: The experimental scheme.

\begin{tabular}{lcr}
\hline Environments & Freezing-thawing cycles & Corrosion time/day \\
\hline Marine corrosion & - & $30,110,190$, and 270 \\
Freezing-thawing & 30,60, and 90 & - \\
& 30 & $30,110,190$, and 270 \\
Coupled corrosion and freezing-thawing & 60 & $30,110,190$, and 270 \\
& 90 & $30,110,190$, and 270 \\
\hline
\end{tabular}

110,190 , and 270 days corresponding to $6,21,37$, and 52 years of those in the Lianyungang sea area, respectively. In addition, 30, 60, and 90 freezing-thawing cycles are conducted for all 6 types of concrete, corresponding to $360 / 10$ years, 720/20 years, and 1080/30 years of freezing-thawing cycles/time in Lianyungang sea, respectively [33]. Besides, the influence of coupled marine corrosion and freezingthawing environment on the mechanical properties of admixture concrete is investigated. In this case, admixture concrete samples are firstly subjected to 30, 60, and 90 freezing-thawing cycles and then to the corrosion for 30 days, 110 days, 190 days, and 270 days, respectively.

\section{Results and Discussion}

4.1. Marine Corrosion. Figure 2 shows the variation of chloride ion concentration (CIC) with the depth of sample and corrosion time. It can be seen that the CIC drops sharply from the surface to the interior of samples (Figures 2(a)2(f)), while CIC increases approximately linearly with the corrosion time (Figures 2(g)-2(h)). As for the fly ash concrete (FAC), CIC of C3-1 is the lowest, while the chloride resistance of concrete with other fly ash amounts is slightly improved. Therefore, the concrete with the $20 \%$ fly ash has the optimal resistance to chloride ion. Compared with FAC, the CIC of mineral powder concrete is lower, but its increasing rate is greater, resulting in high $\mathrm{CIC}$ in mineral powder concrete after 190 days of corrosion. It indicates that adding fly ash into concrete has a better long-term resistance to chloride ions than adding mineral powder. Besides, the concrete with both fly ash and mineral powder (C3-7) has the lowest CIC during the entire corrosion process, and its CIC is close to 0 when the sample depth is $15 \mathrm{~mm}$.

Figure 3 shows the variation of UCS and elasticity modulus $E$ with fly ash amount and admixture type of the concrete free from corrosion and freezing-thawing environments. For FAC, 

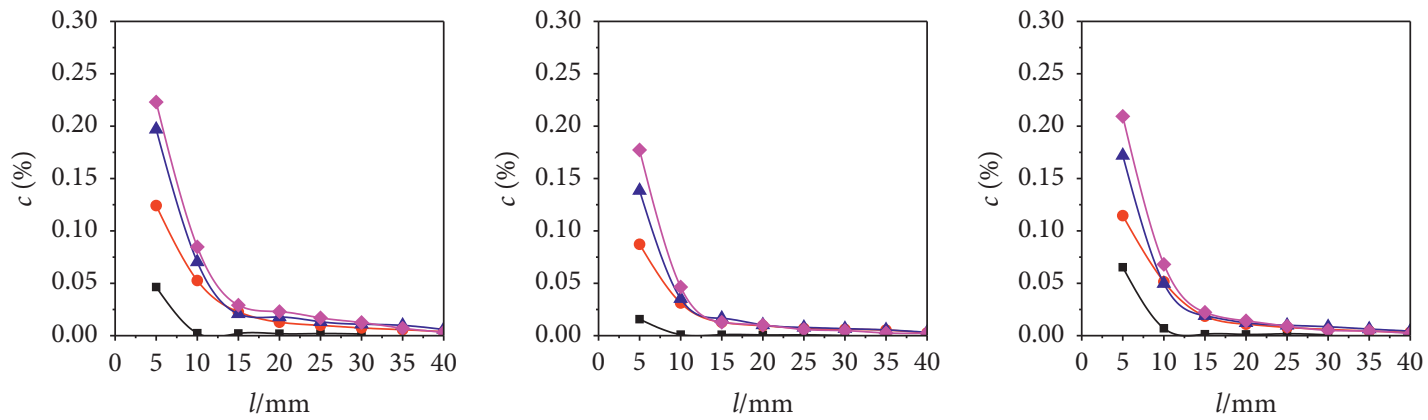

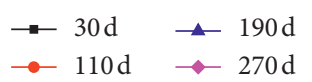

(a)

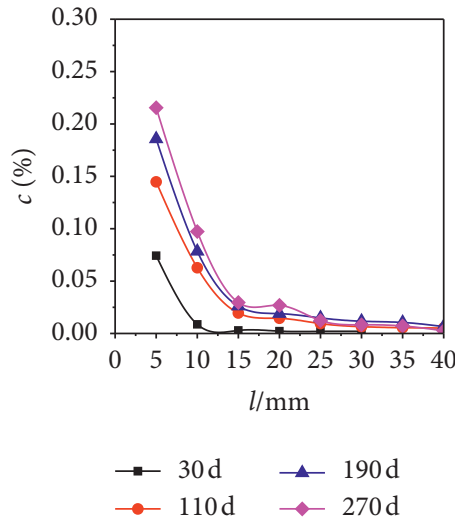

(d)
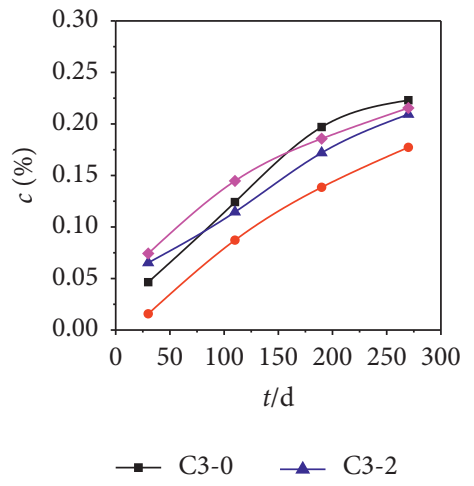$$
\because \mathrm{C} 3-1 \leftrightarrow \mathrm{C} 3-3
$$

(g)
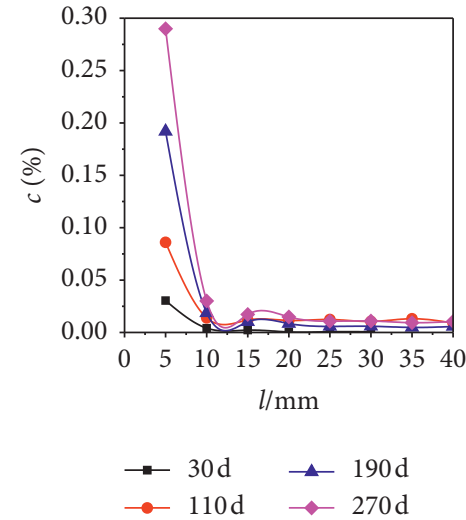

(e)

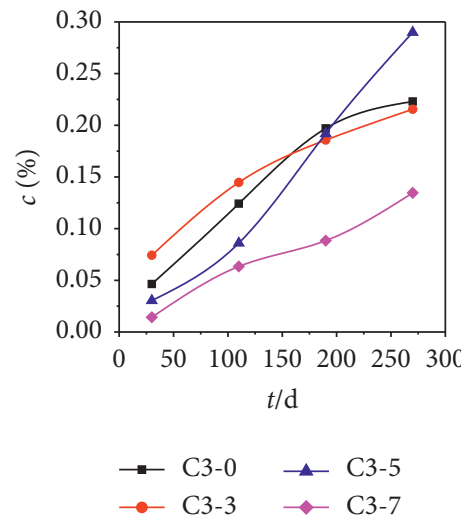

(h)

FIgURE 2: Variation of chloride ion concentration with depth (a-f) and corrosion time $(\mathrm{g}, \mathrm{h})$ under the single corrosion environment.

UCS firstly increases and then decreases with the increase of fly ash content. The UCS of C3-1 (fly ash content: 20\%) is slightly greater than that of C3-0 (ordinary concrete), while $\sigma_{c}$ of C3-2 (fly ash content: $35 \%$ ) and C3-3 (fly ash content: 50\%) is lower than that of C3-0. Compared to the ordinary concrete, only the strength of the C3-7 (the content of fly ash and mineral powder: $15 \%$ and $35 \%$ ) is enhanced, and that of concrete with $50 \%$ of admixtures is decreased. In addition, the effect of admixtures on elasticity is similar to that on UCS. Furthermore, it can be concluded that the concrete with both fly ash and mineral powder has optimal performance on both chloride resistance and compressive strength, which is the excellent admixture scheme for marine concrete. Consequently, the UCS and E of C3-7 after different corrosion time are tested. As shown in Figure 4, the results suggest that both UCS and $E$ increase linearly before 190 days of corrosion, while they decrease remarkably after 290 days of corrosion.

Figure 5(a) shows the pore size distribution of concrete with composite admixture in the erosion environment. The pore size is divided into four regions: $0-30 \mathrm{~nm}$ (I), 30-150 nm (II), $150-4000 \mathrm{~nm}$ (III), and $>4000 \mathrm{~nm}$ (IV). Figure 5(b) shows pore volume ratio of 4 regions; $V_{1}, V_{2}, V_{3}$, and $V_{4}$ are 


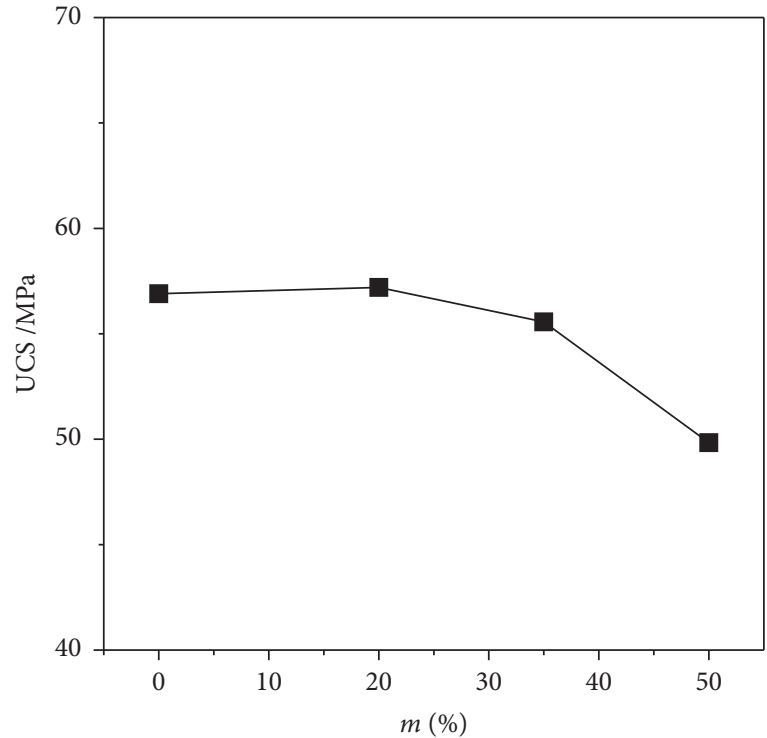

(a)

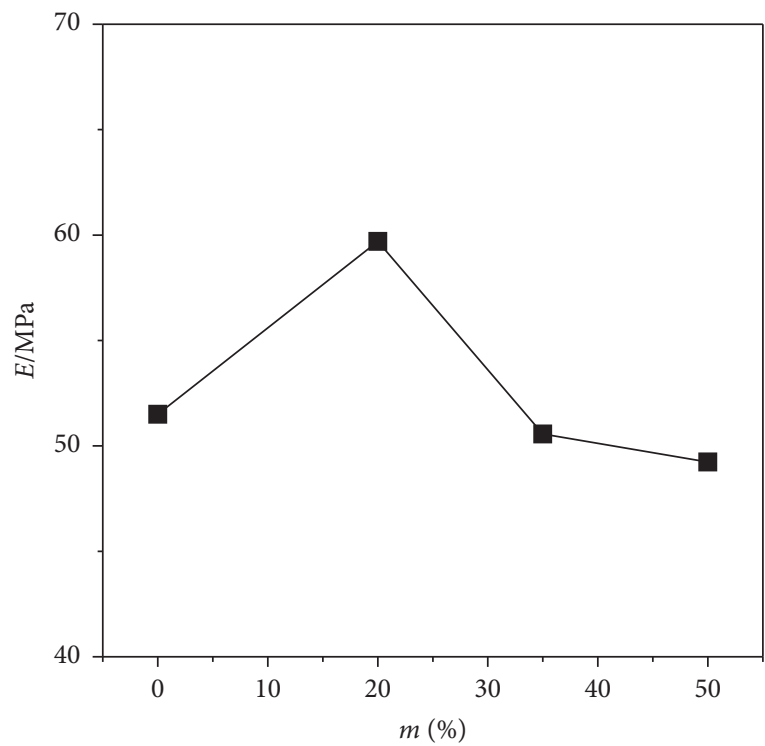

(c)

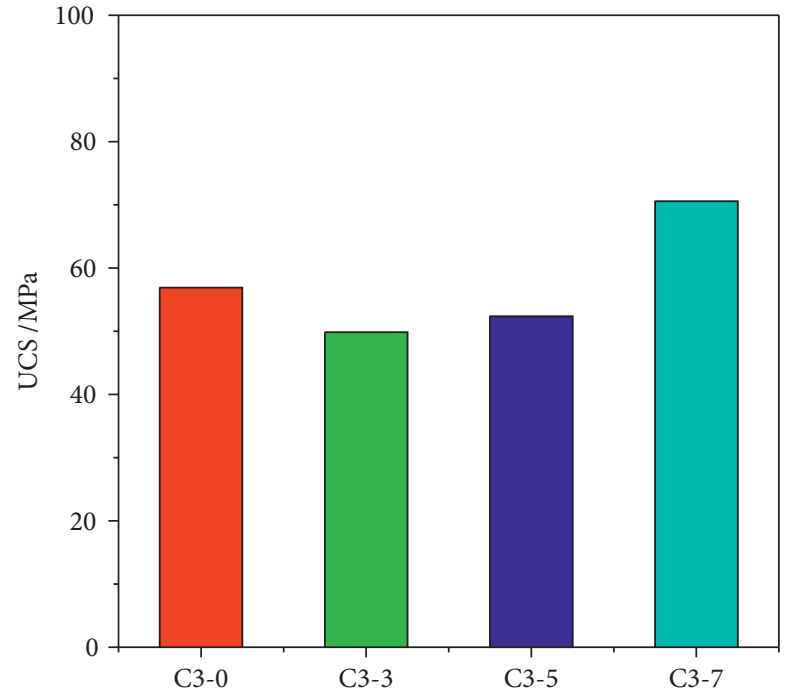

(b)

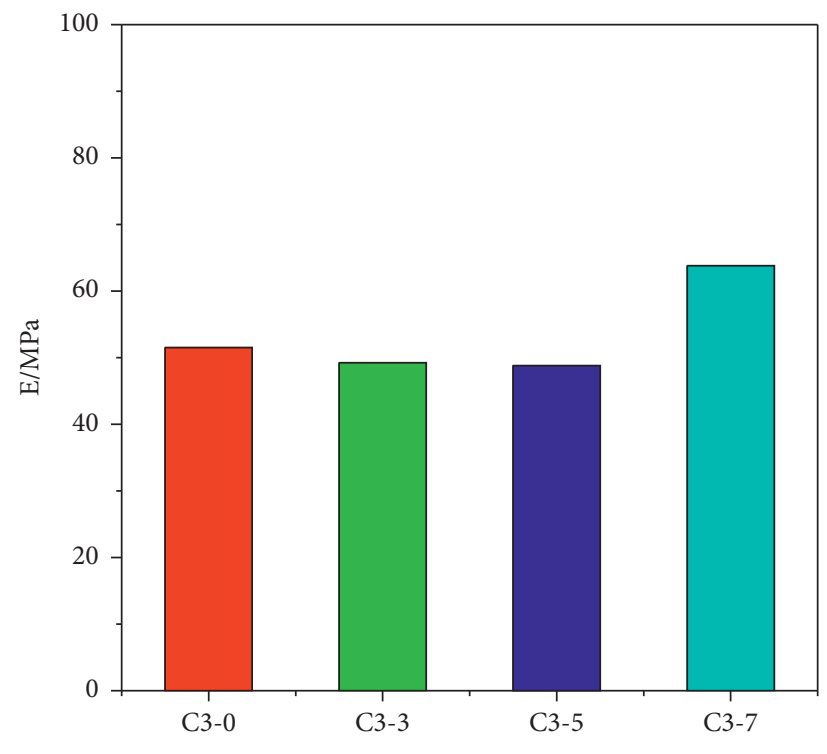

(d)

Figure 3: The variation of uniaxial compressive strength and elasticity modulus with (a, c) different fly ash contents and (b, d) admixture type of the concrete (without corrosion and freezing-thawing environments).

the pore volumes of corresponding region, and $V_{t}$ is the total pore volume. When the chlorine erosion time increases from 30 days to 270 days, the pore diameter distribution is changed as follows: region I decreases, region II increases, region III is almost unchanged, and region IV drops. Due to the secondary hydration of fly ash and mineral powder admixtures for a long time, calcium silicate hydrate (C-S-H) is generated to fill the pores in concrete, resulting in changes in pore distribution. As shown in Figure 6, after 30, 110, 170, and 290 days of corrosion, the secondary hydration in the microstructure of $\mathrm{C} 3-7$ samples is not obvious, while numerous primary cracks are generated after 30 days of corrosion. When the corrosion time increases to 110 days, the primary cracks are filled with hydration products, but the microstructure is relatively compact. As a result, the UCS and $E$ increase after these two corrosion cases. After 190 days of corrosion, due to the invasion of more chloride ions into the concrete, the large volume of crystal salts is produced and concrete cement slurry cracking and cracks are induced; meanwhile mechanical properties of C3-7 samples are increased due to the slight and nonpenetrating cracks. With the increase of the corrosion time, the cracks are connected and the strength of the C3-7 sample is reduced. In a word, the C-S-H induced by secondary hydration can fill concrete to become denser, and the compressive strength of the sample is improved to a certain extent. However, with the increase of corrosion time, C-S-H gradually expands and cracks increase correspondingly, leading to a decrease in the compressive strength of the concrete. 


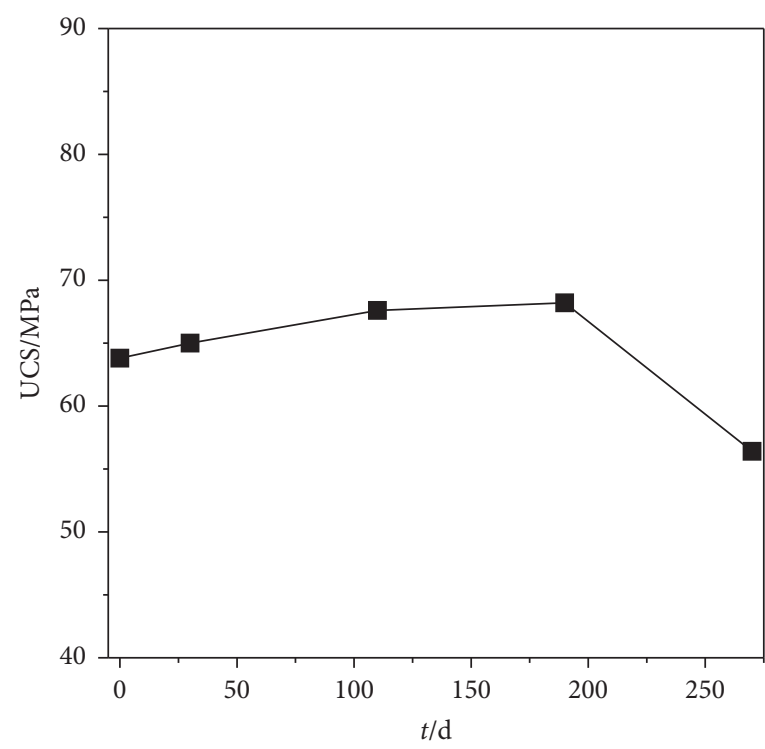

(a)

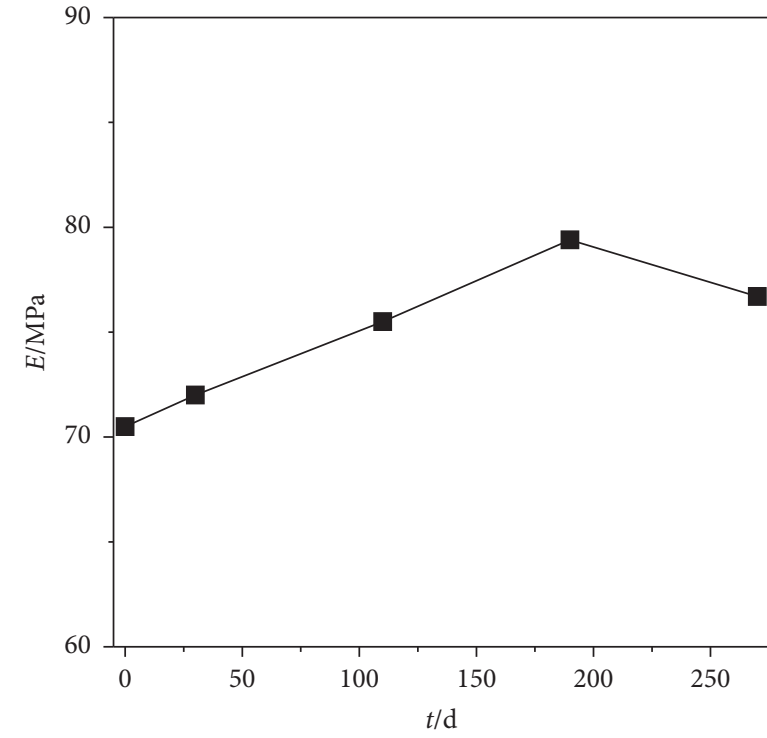

(b)

FIgURE 4: The variation of (a) uniaxial compressive strength and (b) elasticity modulus of C3-7 with the corrosion time.

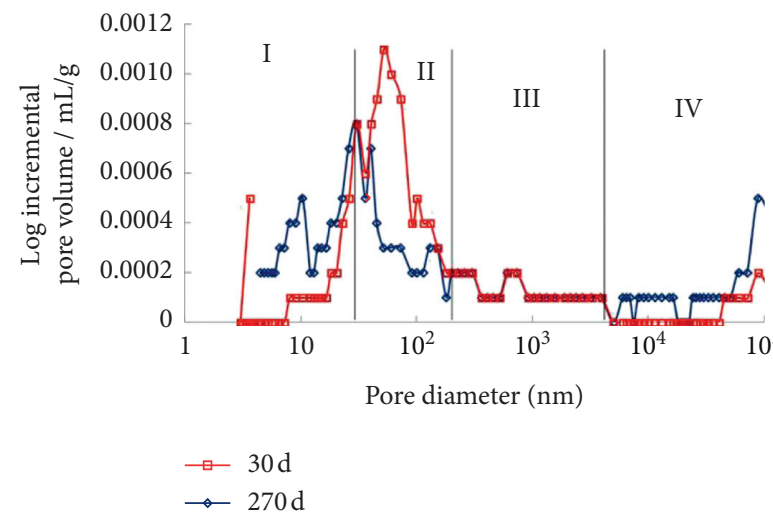

(a)

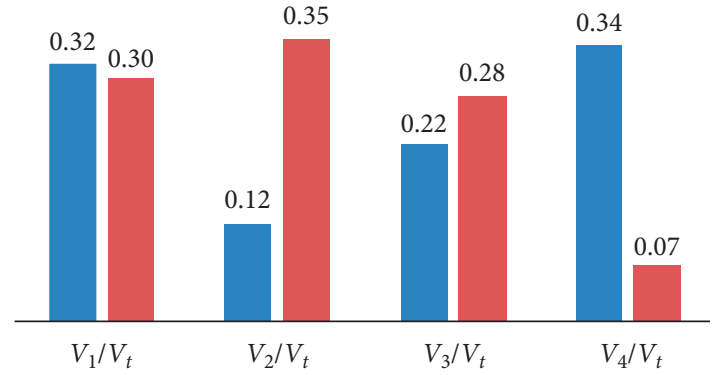

- $30 \mathrm{~d}$

- $270 \mathrm{~d}$

FIgURE 5: Pore size distribution of C3-7 under the marine corrosion environment.

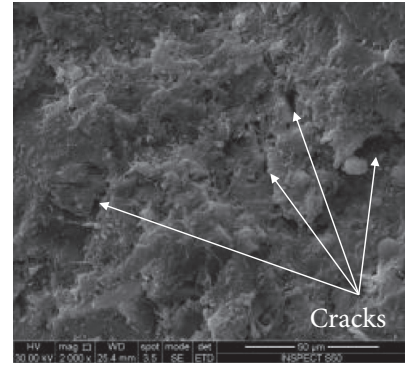

(a)

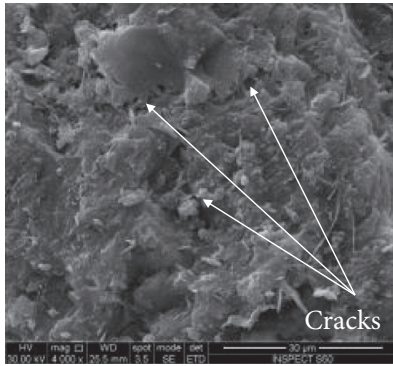

(b)

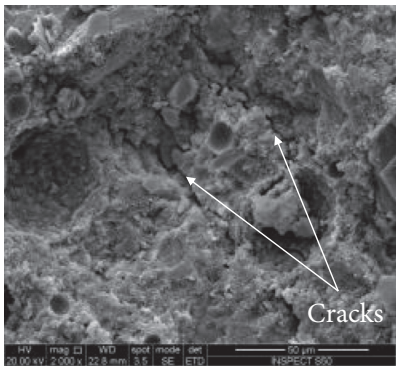

(c)

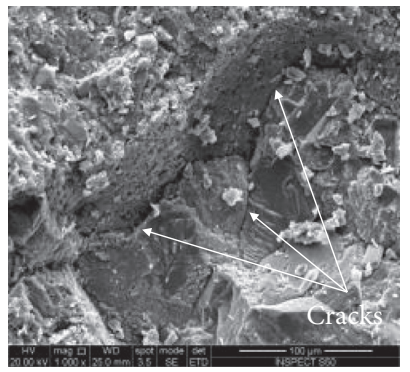

(d)

Figure 6: SEM maps of C3-7 after (a) 30, (b) 110, (c) 190, and (d) 270 days of corrosion.

4.2. Freezing-Thawing Cycles. Figure 7 shows the variation of uniaxial compressive strength and relative dynamic elastic modulus $P$ with the number of freezing-thawing cycles. For the FAC, UCS decreases quasi-linearly with the freezingthawing cycles; $P$ drops gradually in the first 60-70 freezingthawing cycles and then declines rapidly in the subsequent 


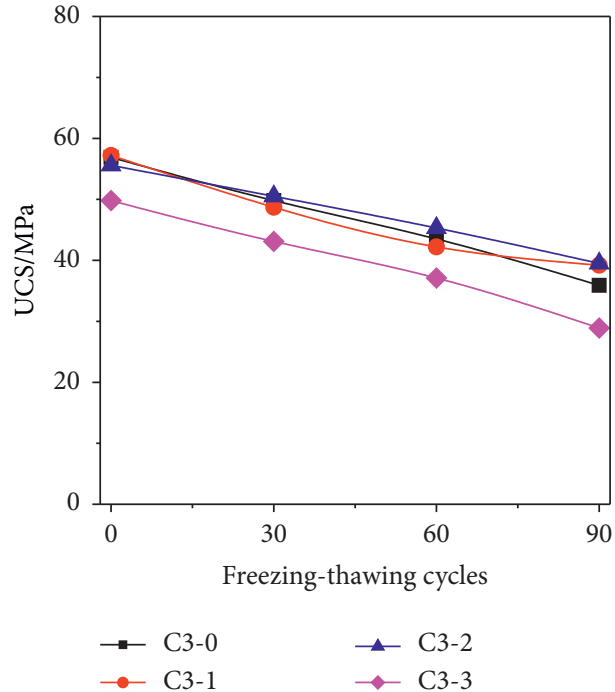

(a)

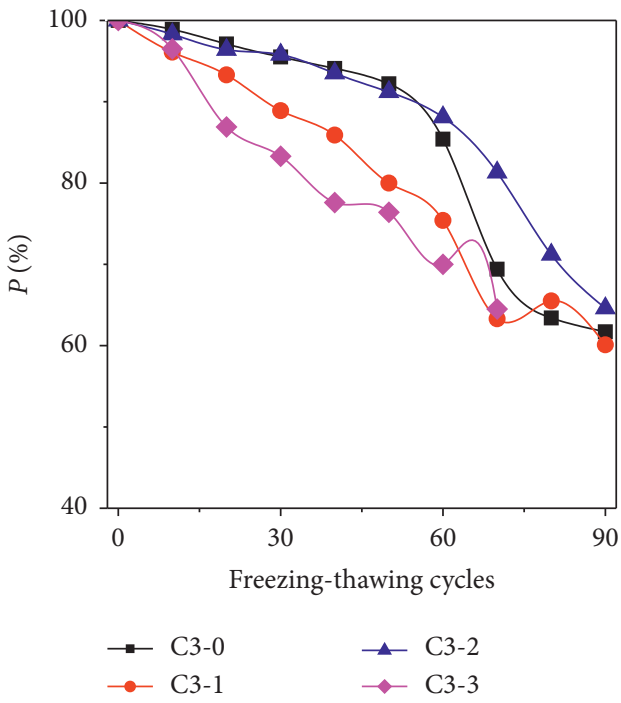

(c)

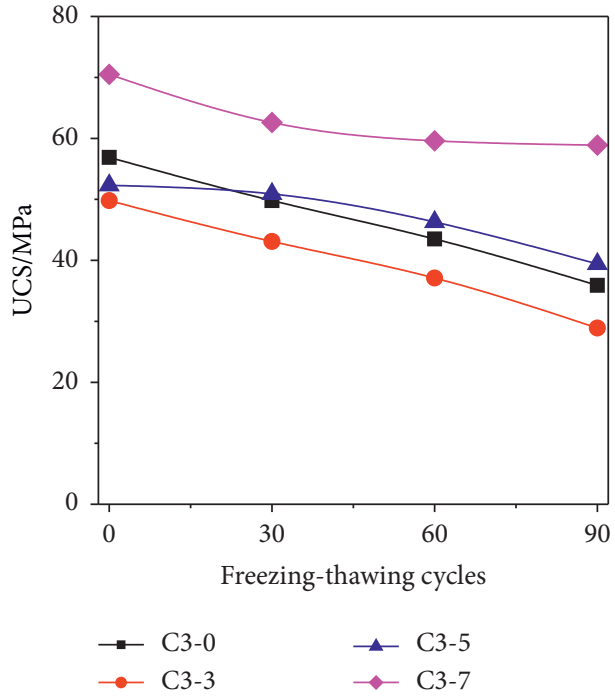

(b)

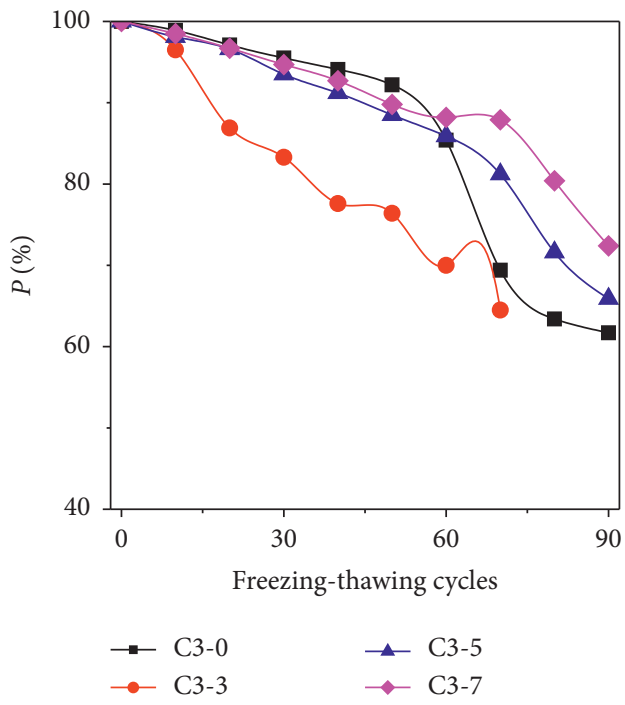

(d)

Figure 7: Variation of $(a, b)$ uniaxial compressive strength and $(c, d)$ relative dynamic elastic modulus with the number of freezing-thawing cycles.

cycles. Compared to the ordinary concrete, the single addition of fly ash into the concrete cannot improve the frost resistance property, and, even after the addition of $50 \%$ of fly ash, its freezing-thawing resistance property is weakened. For the concrete with the fly ash and mineral powder of $50 \%$ (C3-7), UCS and $P$ have similar characteristics to those of FAC, but the frost resistance property of the C3-7 sample is significantly improved. Combined with the corrosion analysis, it can be obtained that the addition of both fly ash and mineral powder to the concrete can effectively improve the corrosion and freezing-thawing resistances.

Figure 8 shows the surface spalling of the concrete after different freezing-thawing cycles. After 30 freezing-thawing cycles, the surfaces of concrete samples are relatively complete. After 60 freezing-thawing cycles, the cement paste on the surface of all samples except C3-7 gradually falls off and some small pit corrosion occurs. The pit corrosion holes of C3-3 samples are relatively large. After 90 freezing-thawing cycles, the concrete samples are damaged to a certain degree, among which the surfaces of the C3-0, C3-1, C3-2, and C3-5 are uneven with the exposed fine aggregate. The surface of the C3-3 is severely denuded, and the fine aggregate gradually falls off, while the surface of the C3-7 remains flat. Figure 9 shows the SEM images of the microstructure of the composite concrete (C3-7) sample after 30, 60, and 90 freezing-thawing cycles. With the increase of freezing-thawing times, the surface of the concrete mesoscopic structure becomes uneven and loose, and the internal cracks increase. In Figure 9(a), there are fewer cracks and shorter crack lengths, but, in Figure 9(c), there are more microcracks and long cracks. 


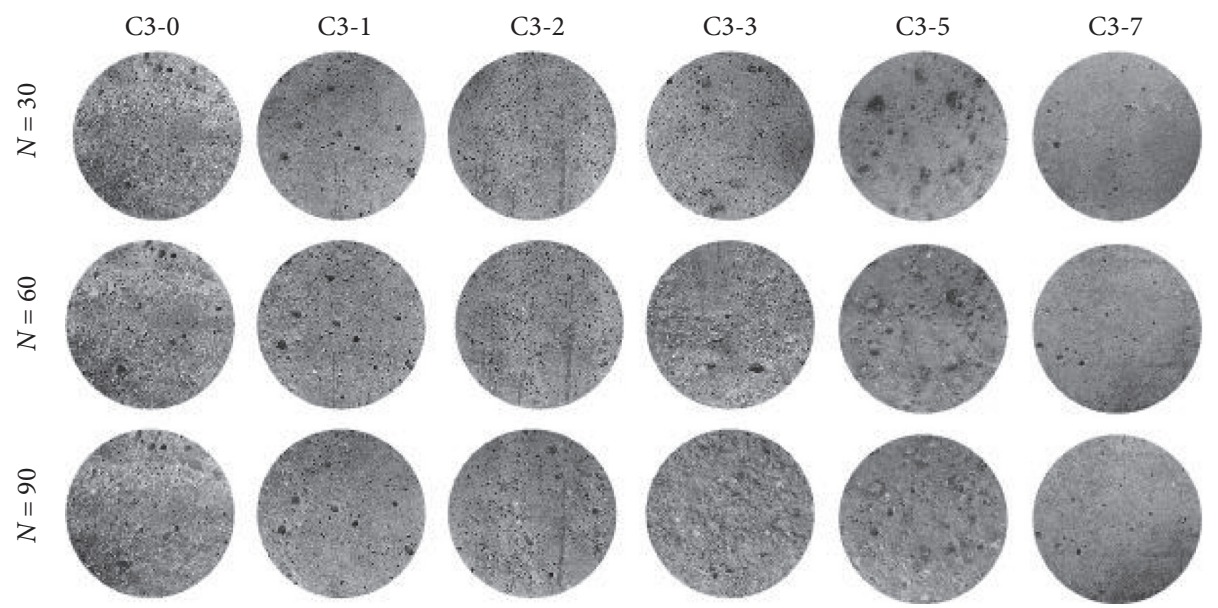

FIGURE 8: Surface spalling for concrete after different freezing-thawing cycles.

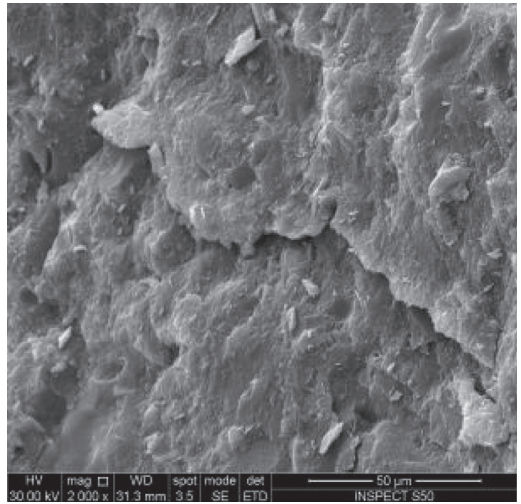

(a)

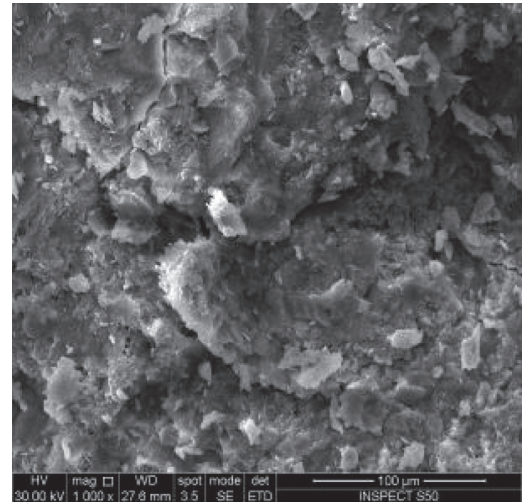

(b)

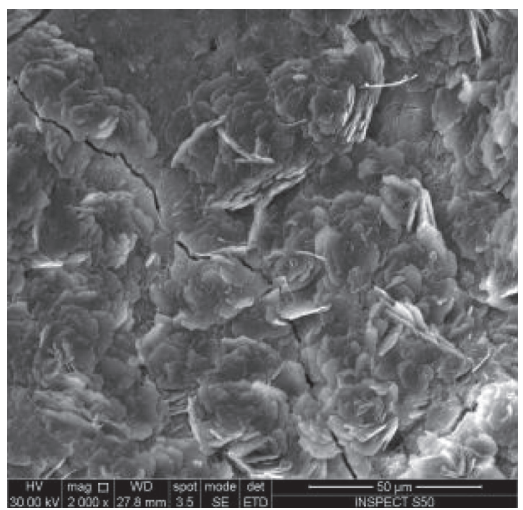

(c)

FIGURE 9: SEM maps of C3-7 after (a) 30, (b) 60, and (c) 90 freezing-thawing cycles.

4.3. Coupled Marine Corrosion and Freezing-Thawing Environment. Figure 10 shows the variation of CIC with the corrosion time for fly ash concrete after different freezingthawing cycles. Obviously, the CIC of FAC is significantly increased after freezing-thawing, and the CIC difference between freezing-thawing and non-freezing-thawing extends with the increase of freezing-thawing cycles. Compared to C3-0 (ordinary concrete), the chloride resistance of C3-1 (fly ash content: 20\%) is improved significantly after 110 days of corrosion under 30,60, and 90 freezing-thawing cycles. Figure 11 shows the $\mathrm{CIC}$ with corrosion time for the concrete with 50\% admixture. As shown in Figure 11, C3-5 (mineral power content: 50\%) exhibits lower CIC than adding fly ash to the concrete after freezing-thawing cycles, and C3-7 can resist chloride and freezing-thawing more efficiently than concrete with other admixture schemes and has the prime chloride resistance after freezing-thawing cycles.

The uniaxial compressive strengths of the C3-7 under various corrosion times after different freezing-thawing cycles are tested, and the results are shown in Figure 12. It can be seen that the UCS after the freezing-thawing is generally lower than that of samples subjected to the single corrosion. The UCS after both freezing-thawing and nonfreezing-thawing increases first and then decreases with the growth of corrosion time. This characteristic indicates that the marine corrosion environment is beneficial to the mechanical property of the concrete within short time corrosion, while it is harmful in long-time corrosion.

Figure 13 shows the SEM maps of C3-7 eroded for 30 and 270 days after 90 freezing-thawing cycles. After 30 days of corrosion, there are still a large number of calcium hydroxide hexagonal crystals $(\mathrm{CH})$ and long hexagonal prismatic ettringite (AFt) in the mixed concrete, and there are more reticular and needle-like C-S-H gels, all of which are typical hydration products of ordinary Portland cement. After 270 days of corrosion, $\mathrm{CH}$ and AFt in the concrete are replaced by the layered $\mathrm{C}-\mathrm{S}-\mathrm{H}$ because the secondary hydration of fly ash consumes numerous $\mathrm{CH}$ crystals, and the newly formed C-S-H is filled with concrete in the small pore (region I) and larger pore (region IV). Thus, the volume of pores in the small pore (region I) and larger pore (region IV) decreases (Figure 14). In addition, due to the corrosion of chloride ion, a large number of crystal salts are generated, 
which may fill the pores or create new pores due to
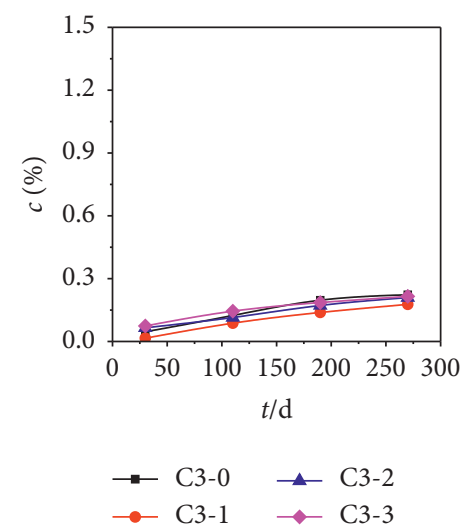

(a)
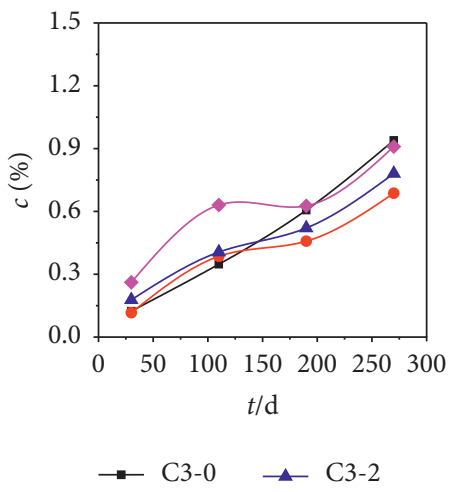

$\rightarrow \mathrm{C} 3-1 \rightarrow \mathrm{C} 3-3$

(c) expansion.

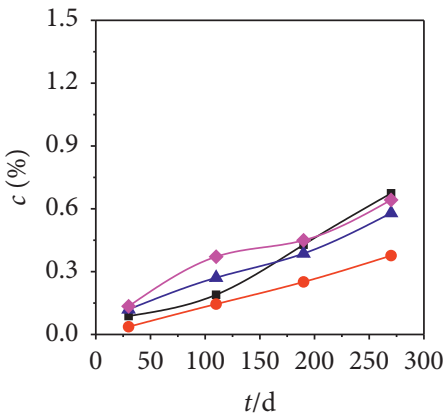

$\rightarrow \mathrm{C} 3-0 \longrightarrow \mathrm{C} 3-2$

$\rightarrow \mathrm{C} 3-1 \rightarrow \mathrm{C} 3-3$

(b)
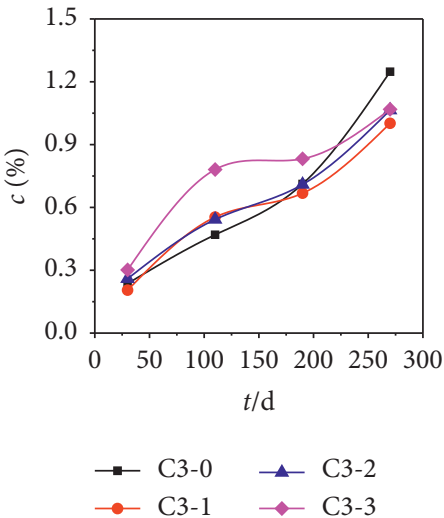

(d)

FIGURE 10: Variation of CIC with corrosion time for fly ash concrete after 0 (a), 30 (b), 60 (c), and 90 (d) freezing-thawing cycles.

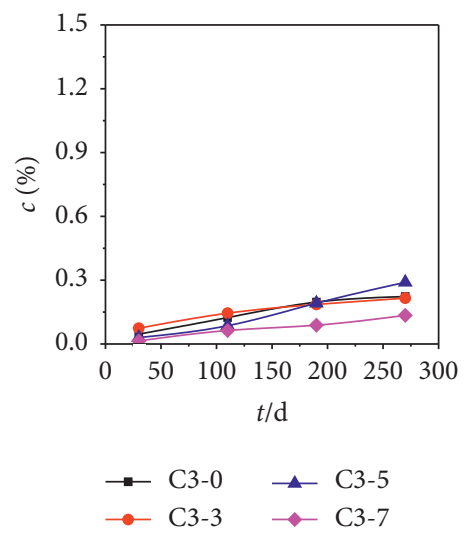

(a)

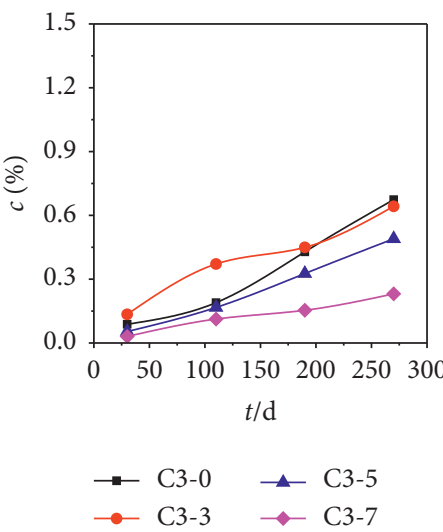

(b)

FIgUre 11: Continued. 


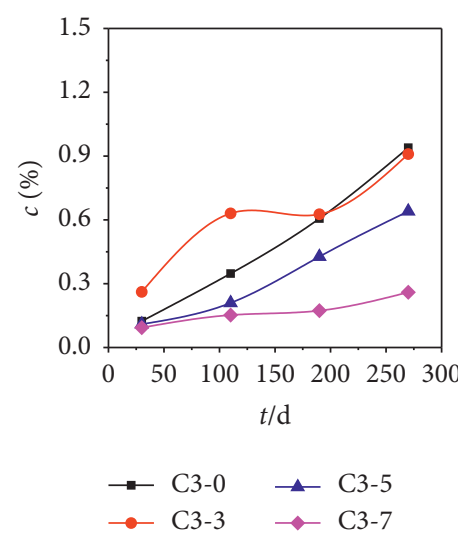

(c)

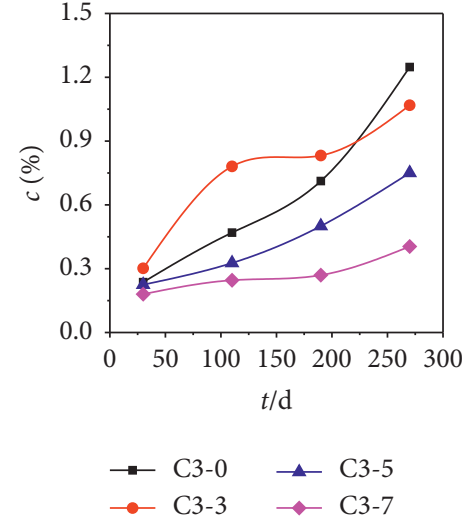

(d)

FiguRE 11: Variation of CIC with corrosion time for the concrete with 50\% admixture after 0 (a), 30 (b), 60 (c), and 90 (d) freezing-thawing cycles.

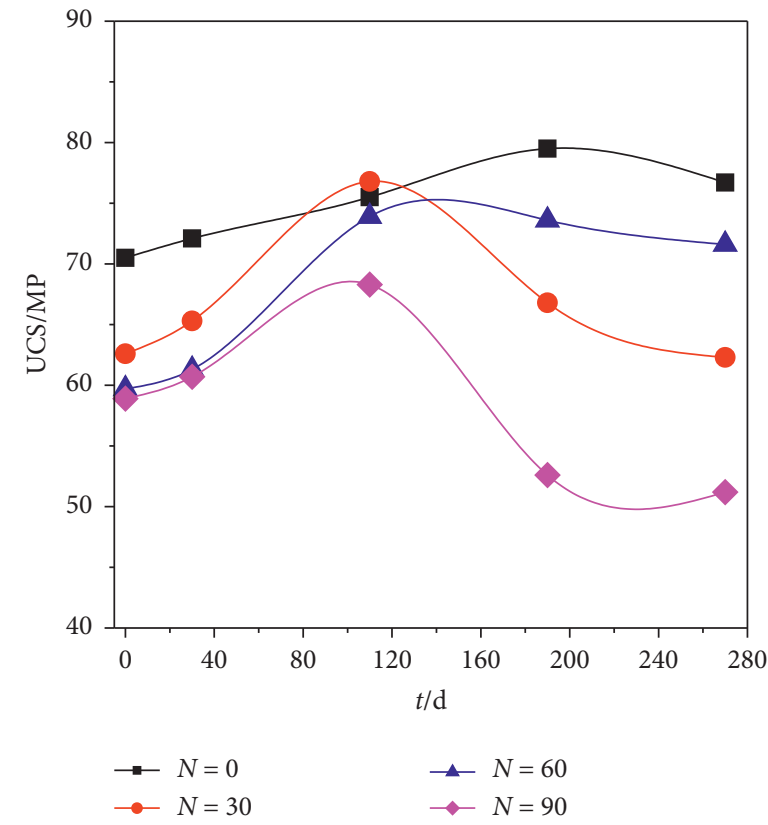

FIGURE 12: Curves of concrete strength $\sigma_{c}$ with the corrosion time after different freezing-thawing cycles.

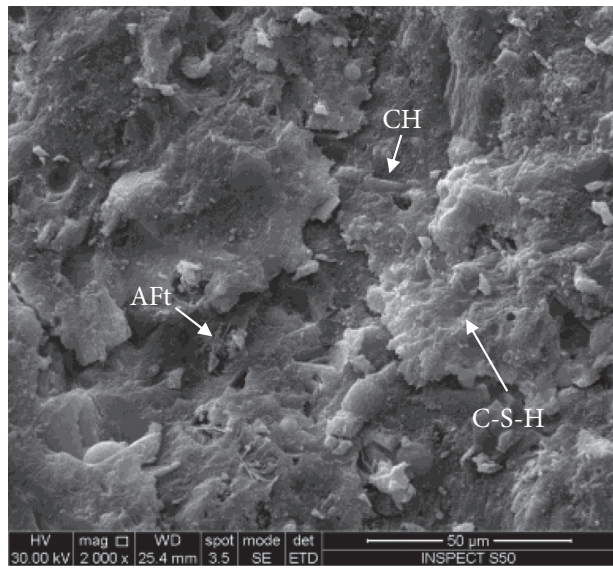

(a)

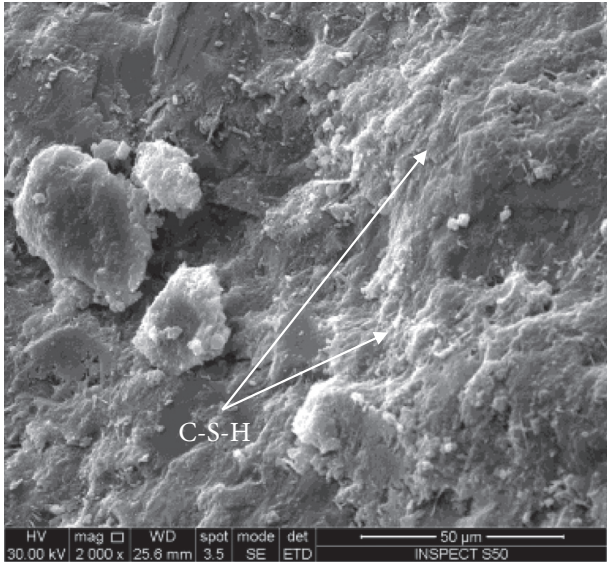

(b)

FIgURE 13: SEM maps of C3-7 under (a) 30 days and (b) 270 days of corrosion after 90 freezing-thawing cycles. 


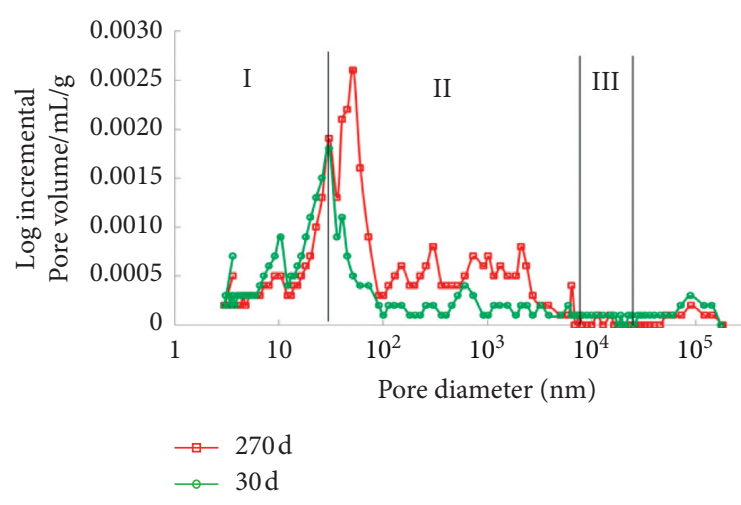

(a)

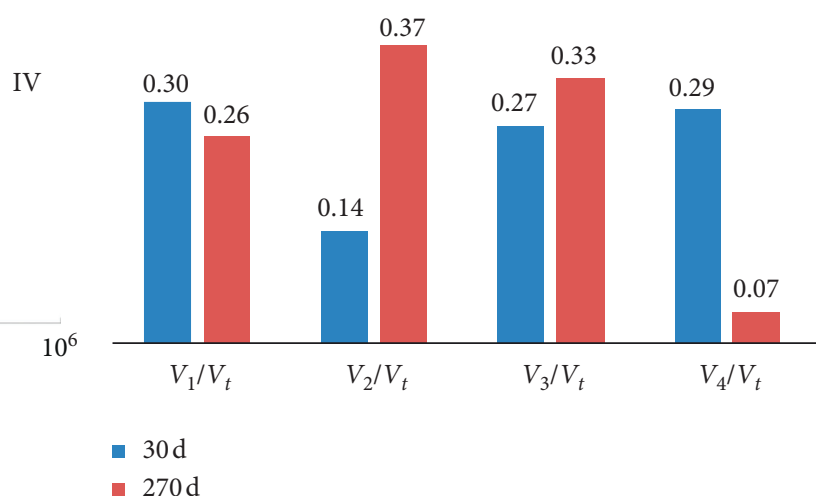

(b)

FIGURE 14: Pore size distribution of C3-7 under coupled corrosion and freezing-thawing environment.

To describe the effect of coupled corrosion and freezingthawing on the mechanical property of the concrete, a freezing-thawing-corrosion composite strength impact factor is introduced as follows:

$$
\sigma_{c i j}=\lambda_{i j} \sigma_{c 00}
$$

where $i$ and $j$ represent freezing-thawing cycles and corrosion time, respectively; $\sigma_{c i j}$ is the compression strength of the concrete subjected with $i$ freezing-thawing cycles and subsequent $j$ days of corrosion; $\lambda_{i j}$ is the freezing-thawingcorrosion composite strength impact factor of the concrete subjected with $i$ freezing-thawing cycles and subsequent $j$ days of corrosion. If $\lambda=1.0$, it indicates that the coupled corrosion and freezing-thawing have no effect on the strength of concrete; if $\lambda>1.0$, there is a positive effect; and if $\lambda<1.0$, there is a negative effect.

Table 3 shows the values of $\lambda$ under various $i$ and $j$. It can be seen that the composite strength impact factor under some cases is greater than 1.0 but smaller than 1.0 under other cases. This result indicates that the influence of coupled freezing-thawing and corrosion environment on the concrete is uncertain. If the number of freeze-thaw cycles is 90 , any $\lambda$ is less than 1.0, indicating that the UCS of concrete is reduced by the coupled freezing-thawing and corrosion. In addition, under the coupled freezing-thawing and corrosion $(i=90, j=190 ; i=90, j=270)$, the composite strength impact factor is lower than that under single factor action $(i=90, j=0 ; i=0, j=270)$. It indicates that composite factors aggravate the deterioration degree of the concrete.

In fact, during a period of chlorine corrosion, the invading chloride ions react with other components in the concrete; then large crystal salts are generated and fill the pores of the concrete. As a result, the concrete microstructure becomes more compact by the action of cement and other substances. Besides, the hydration reaction of concrete and the secondary hydration reaction of admixtures are more sufficient, which effectively improves the compressive strength of concrete. When the invasion of chlorine salt reaches a certain value, the concrete is damaged and its mechanical properties are reduced. Freezing-thawing
TABLE 3: Composite strength impact factor $\lambda$ with the freezingthawing cycles $i$ and corrosion time $j$ of C3-7.

\begin{tabular}{lccccc}
\hline$i$ & & \multicolumn{5}{c}{$\lambda$} \\
& $j=0 \mathrm{~d}$ & $j=30 \mathrm{~d}$ & $j=110 \mathrm{~d}$ & $j=190 \mathrm{~d}$ & $j=270 \mathrm{~d}$ \\
\hline 0 & 1.00 & 1.01 & 1.05 & 1.10 & 1.07 \\
30 & 0.86 & 0.90 & 1.06 & 0.92 & 0.86 \\
60 & 0.82 & 0.84 & 1.02 & 1.01 & 0.98 \\
90 & 0.81 & 0.83 & 0.94 & 0.72 & 0.70 \\
\hline
\end{tabular}

mainly loosens and damages the pore structure of concrete by crystal water and nonuniform change of material volume; then the mechanical properties and compressive strength of concrete are reduced. According to the test results and analysis, the strength complex influence factor is mainly dependent on the influence status of the two factors under the action of freezing-thawing and chlorine corrosion coupling. The results show that the corrosion factor is the dominant factor after 0,30 , and 60 freezing-thawing cycles, and the composite strength impact factor is larger; the freezing-thawing factor is the dominant factor after 90 freezing-thawing cycles, and the composite strength impact factor is smaller. It can be seen that the effect of coupling environmental action on concrete strength is not a single superposition.

\section{Conclusions}

To reveal the damage mechanism of admixture concrete in marine environment, uniaxial compressive tests and scanning electron microscope tests on admixture concrete samples are conducted under the single marine corrosion, the single freezing-thawing, and the coupled marine corrosion and freezing-thawing conditions. The main conclusions are obtained as follows:

(1) The UCS, chloride ion penetration resistance, and freezing-thawing resistance of the concrete with the addition of both fly ash and mineral powder are more excellent than those with the single fly ash or mineral powder. 
(2) Under the marine corrosion and the coupled corrosion and freezing-thawing environment, the UCS of the concrete with the addition of both fly ash and mineral powder increases firstly and then decreases with the increase of the corrosion time. This is because the pore of the filling body is filled by large crystalline salts generated by the reaction of chloride ions and concrete; then the cementation of the cement is increased in the early corrosion. However, the increase of crystalline salts in the subsequent corrosion process leads to the growth of microcracks and the formation of macrocracks in concrete specimens.

(3) A freezing-thawing-corrosion composite strength impact factor is introduced to describe the effect of coupled corrosion and freezing-thawing on the mechanical property of the concrete. The results show that corrosion is the dominant factor after 0 , 30 , and 60 freezing-thawing cycles, while the freezing-thawing is the dominant factor after 90 freezing-thawing cycles.

\section{Data Availability}

The data used to support the findings of this study are included within the article.

\section{Conflicts of Interest}

The authors declare that they have no conflicts of interest.

\section{Acknowledgments}

Li Yan acknowledges the Key Research and Development Program of Xuzhou (no. KC18090). Ma Chao acknowledges the Key Research and Development Program of Xuzhou (no. KC20176). Zhang Lianying was supported by the National Natural Science Foundation of China (nos. 51974296 and 52074240). Zhu Jiong was supported by the Innovation Capacity Building Program of Xuzhou (no. KC18241).

\section{References}

[1] R. Vera, M. Villarroel, A. M. Carvajal, E. Vera, and C. Ortiz, "Corrosion products of reinforcement in concrete in marine and industrial environments," Materials Chemistry and Physics, vol. 114, no. 1, pp. 467-474, 2009.

[2] T. R. Naik, "Sustainability of concrete construction," Practice Periodical on Structural Design and Construction, vol. 13, no. 2, pp. 98-103, 2008.

[3] Y. Chen, G. E. Okudan, and D. R. Riley, "Sustainable performance criteria for construction method selection in concrete buildings," Automation in Construction, vol. 19, no. 2, pp. 235-244, 2010.

[4] N. D. Oikonomou, "Recycled concrete aggregates," Cement and Concrete Composites, vol. 27, no. 2, pp. 315-318, 2005.

[5] B. A. G. Bossink and H. J. H. Brouwers, "Construction waste: quantification and source evaluation," Journal of Construction Engineering and Management, vol. 122, no. 1, pp. 55-60, 1996.
[6] B. Li, L. Cai, and W. Zhu, "Predicting service life of concrete structure exposed to sulfuric acid environment by grey system theory," International Journal of Civil Engineering, vol. 16, no. 9, pp. 1017-1027, 2018.

[7] D. Ma, J. X. Zhang, H. Y. Duan et al., "Reutilization of gangue wastes in underground backfilling mining: overburden aquifer protection," Chemosphere, vol. 264, no. 1, Article ID 128400, 2021.

[8] G. De Schutter, K. Lesage, V. Mechtcherine, V. N. Nerella, G. Habert, and I. Agusti-Juan, "Vision of 3D printing with concrete-technical, economic and environmental potentials," Cement and Concrete Research, vol. 112, pp. 25-36, 2018.

[9] L. Basheer, J. Kropp, and D. J. Cleland, “Assessment of the durability of concrete from its permeation properties: a review," Construction and Building Materials, vol. 15, no. 2-3, pp. 93-103, 2001.

[10] H. Van Damme and H. Houben, "Earth concrete. stabilization revisited," Cement and Concrete Research, vol. 114, pp. 90-102, 2018.

[11] D. Ma, H. Duan, W. Liu, X. Ma, and M. Tao, "Water-sediment two-phase flow inrush hazard in rock fractures of overburden strata during coal mining," Mine Water and the Environment, vol. 39, no. 2, pp. 308-319, 2020.

[12] D. Ma, H. Duan, Q. Zhang et al., "A numerical gas fracturing model of coupled thermal, flowing and mechanical effects," Computers, Materials \& Continua, vol. 65, no. 3, pp. 2123-2141, 2020.

[13] P. Nath, P. K. Sarker, and W. K. Biswas, "Effect of fly ash on the service life, carbon footprint and embodied energy of high strength concrete in the marine environment," Energy and Buildings, vol. 158, pp. 1694-1702, 2018.

[14] Q. Wang, R. Pan, B. Jiang et al., "Study on failure mechanism of roadway with soft rock in deep coal mine and confined concrete support system," Engineering Failure Analysis, vol. 81, pp. 155-177, 2017.

[15] K. Ebrahimi, M. J. Daiezadeh, M. Zakertabrizi, F. Zahmatkesh, and A. Habibnejad Korayem, "A review of the impact of micro- and nanoparticles on freeze-thaw durability of hardened concrete: mechanism perspective," Construction and Building Materials, vol. 186, pp. 1105-1113, 2018.

[16] B. Hou, X. Li, X. Ma et al., "The cost of corrosion in China," NPJ Materials Degradation, vol. 1, no. 1, p. 4, 2017.

[17] J. Zuquan, Z. Xia, Z. Tiejun, and L. Jianqing, "Chloride ions transportation behavior and binding capacity of concrete exposed to different marine corrosion zones," Construction and Building Materials, vol. 177, pp. 170-183, 2018.

[18] T. Cheewaket, C. Jaturapitakkul, and W. Chalee, "Initial corrosion presented by chloride threshold penetration of concrete up to 10 year-results under marine site," Construction and Building Materials, vol. 37, pp. 693-698, 2012.

[19] T. Nishida, N. Otsuki, H. Ohara, Z. M. Garba-Say, and T. Nagata, "Some considerations for applicability of seawater as mixing water in concrete," Journal of Materials in Civil Engineering, vol. 27, no. 7, 2013.

[20] R. E. Melchers and C. Q. Li, "Reinforcement corrosion initiation and activation times in concrete structures exposed to severe marine environments," Cement and Concrete Research, vol. 39, no. 11, pp. 1068-1076, 2009.

[21] A. H. Memon, S. S. Radin, M. F. M. Zain, and J.-F. Trottier, "Effects of mineral and chemical admixtures on high-strength concrete in seawater," Cement and Concrete Research, vol. 32, no. 3, pp. 373-377, 2002. 
[22] M. Valipour, M. Shekarchi, and M. Arezoumandi, "Chlorine diffusion resistivity of sustainable green concrete in harsh marine environments," Journal of Cleaner Production, vol. 142, pp. 4092-4100, 2017.

[23] W. Ahn and D. V. Reddy, "Galvanostatic testing for the durability of marine concrete under fatigue loading," Cement and Concrete Research, vol. 31, no. 3, pp. 343-349, 2001.

[24] C. Medina, M. I. Sánchez de Rojas, and M. Frías, "Freeze-thaw durability of recycled concrete containing ceramic aggregate," Journal of Cleaner Production, vol. 40, pp. 151-160, 2013.

[25] F. Gong, Y. Wang, D. Zhang, and T. Ueda, "Mesoscale simulation of deformation for mortar and concrete under cyclic freezing and thawing stress," Journal of Advanced Concrete Technology, vol. 13, no. 6, pp. 291-304, 2015.

[26] F. Chen and P. Qiao, "Probabilistic damage modeling and service-life prediction of concrete under freeze-thaw action," Materials and Structures, vol. 48, no. 8, pp. 2697-2711, 2015.

[27] R. Polat, "The effect of antifreeze additives on fresh concrete subjected to freezing and thawing cycles," Cold Regions Science and Technology, vol. 127, pp. 10-17, 2016.

[28] D. Niu, L. Jiang, M. Bai, and Y. Miao, "Study of the performance of steel fiber reinforced concrete to water and salt freezing condition," Materials \& Design, vol. 44, pp. 267-273, 2013.

[29] T. Gonen, S. Yazicioglu, and B. Demirel, "The influence of freezing-thawing cycles on the capillary water absorption and porosity of concrete with mineral admixture," KSCE Journal of Civil Engineering, vol. 19, no. 3, pp. 667-671, 2015.

[30] H. Ma, H. Yu, and W. Sun, "Freezing-thawing durability and its improvement of high strength shrinkage compensation concrete with high volume mineral admixtures," Construction and Building Materials, vol. 39, pp. 124-128, 2013.

[31] K. Sun, Z. Hu, H. Mao, and R. Zhang, "Period and jump analysis of temperature variation in Daqing in 40 recent years," Marine Forecasts, vol. 24, no. 3, pp. 108-111, 2007, in Chinese.

[32] A. Dousti, R. Rashetnia, B. Ahmadi, and M. Shekarchi, "Influence of exposure temperature on chloride diffusion in concretes incorporating silica fume or natural zeolite," Construction and Building Materials, vol. 49, pp. 393-399, 2013.

[33] J. Li and Z. Wang, "Quantitative design of frost resistance of concrete," Concrete, vol. 12, pp. 61-62, 2000. 